\title{
QUALIDADE FISIOLÓGICA E POTENCIAL DE ARMAZENAMENTO DE SEMENTES DE CARAMBOLA ${ }^{1}$
}

\author{
MARCIA TEREZINHA RAMOS DE OLIVEIRA², PEDRO AMORIM BERBERT ${ }^{3}$, ROZIMAR DE CAMPOS PEREIRA $^{4}$, \\ HENRIQUE DUARTE VIEIRA ${ }^{5}$, JOSÉ TARCÍSIO LIMA THIÉBAUT' ${ }^{6}$, VINICIUS DE OLIVEIRA CARLESSO ${ }^{7}$
}

\begin{abstract}
RESUMO - O experimento foi realizado com objetivo de avaliar a qualidade fisiológica das sementes de carambola secadas por convecção a $38{ }^{\circ} \mathrm{C}$, por meio do teste de germinação em rolo de papel com duração de 84 dias. Avaliou-se, também, o potencial de armazenamento empregando-se dois tipos de embalagem, permeável e impermeável, sob duas condições de estocagem, ambiente a 25 ${ }^{\circ} \mathrm{C}$ e $61 \%$ de umidade relativa e câmara a $10{ }^{\circ} \mathrm{C}$ e $82 \%$ de umidade relativa, ao longo de 90 e 180 dias. Obteve-se germinação média de $87 \%$ para sementes recém-retiradas dos frutos. Os resultados revelaram que as sementes podem ser armazenadas em embalagem impermeável a vácuo, sem redução do poder germinativo, por 90 ou 180 dias a $10^{\circ} \mathrm{C}$, e por 90 dias em condição do ambiente. As sementes podem, também, ser armazenadas por 90 dias, sob refrigeração, em embalagem permeável. Independentemente do período e da temperatura de armazenamento, o vigor estimado pelo índice de velocidade de germinação (IVG) e pelo tempo médio de germinação $\left(t_{\text {médio }}\right)$, é consistentemente superior para as sementes estocadas em embalagens impermeáveis a vácuo.
\end{abstract}

Termos para indexação: Averrhoa carambola; germinação, índices de vigor, embalagem.

\section{PHYSIOLOGICAL QUALITY AND STORABILITY OF CARAMBOLA SEEDS}

\begin{abstract}
This study was conducted to determine the physiological quality of carambola seeds convectively dried at $38{ }^{\circ} \mathrm{C}$, at the end of germination tests in paper rolls and lasting 84 days. Seed storability using two types of packaging, water vapour permeable and impermeable, under two storage conditions, ambient at $25{ }^{\circ} \mathrm{C}$ and $61 \%$ relative humidity, and inside a $10{ }^{\circ} \mathrm{C}$ refrigerated chamber with relative humidity of $82 \%$, was also assessed for periods of 90 and 180 days. Mean germination percentage of fresh seeds was $87 \%$. The results obtained through germination testing showed that carambola seeds can be stored for 90 or 180 days at $10{ }^{\circ} \mathrm{C}$, or for 90 days at ambient conditions, in vacuum-sealed packaging, without impairing their physiological quality. Seeds may also be stored for 90 days in water vapour-permeable packaging under refrigeration. Vigour estimated through the germination speed index and the mean time of germination was consistently higher for seeds stored in vacuum-sealed packaging, irrespective of storage time and temperature.
\end{abstract}

Index terms: Averrhoa carambola; germination, vigour indices, packaging.

${ }^{1}$ Submetido em 04/11/2008. Aceito para publicação, 13/04/2009.

${ }^{2}$ Tecnóloga em Horticultura, Doutoranda do Programa de Pós-graduação em Produção Vegetal, Universidade Estadual do Norte Fluminense Darcy Ribeiro (UENF), CEP 28013-602 Campos dos Goytacazes, RJ. E-mail:maroli@uenf.br.

${ }^{3}$ Eng. Agrícola, Ph.D., Prof. Associado - UENF/CCTA/LEAG. Campos dos Goytacazes-RJ. E-mail: pberbert@uenf.br.

${ }^{4}$ Eng. Florestal, D.Sc., Profa. Adjunta - UFRB. Cruz das Almas-BA.
E-mail: rozimarcp@uol.com.br

${ }^{5}$ Eng. Agr., D.Sc., Prof. Associado - UENF/CCTA/LFIT. Campos dos Goytacazes-RJ. E-mail: henrique@uenf.br.

${ }^{6}$ Eng. Agr., D.Sc., Prof. Associado - UENF/CCTA/LEAG. Campos dos Goytacazes-RJ. E-mail: jtt1512@uenf.br.

${ }^{7}$ Eng. Agr., M.Sc., Doutorando em Produção Vegetal - UENF/LEAG. E-mail: carlesso@uenf.br. 


\section{INTRODUÇÃO}

A caramboleira (Averrhoa carambola L.), frutífera exótica pertencente à família Oxalidaceae, é originária do sudoeste asiático, mas encontra-se atualmente dispersa em regiões tropicais e em áreas quentes de regiões subtropicais de todos os continentes (Nakasone \& Paull, 1998). É cultivada em pomares domésticos em praticamente todo o Brasil, exceto em regiões frias ou sujeitas a geadas, havendo, entretanto, poucas plantações comerciais (Donadio et al., 2001). Relatos existentes na literatura a respeito da qualidade fisiológica de sementes de carambola sugerem que a perda de viabilidade ocorreria poucos dias depois de sua retirada dos frutos. Mesmo assim, observa-se que a maioria dos pomares comerciais é originada a partir de sementes. Uma das exceções encontra-se na Flórida (EUA), onde a enxertia, por garfagem ou borbulhia, é o principal método de propagação (Crane, 1994; Donadio et al., 2001).

Ellis et al. (1985) sugeriram que as sementes de todas as mais de 500 espécies da família Oxalidaceae apresentariam comportamento ortodoxo durante o armazenamento. Afirmaram, apesar de não haverem apresentado informações sobre o processo de germinação e a ocorrência de mecanismos de dormência, que, à primeira vista, seriam comparativamente pequenos os problemas que poderiam ocorrer na realização dos testes de qualidade fisiológica. No entanto, em trabalho mais recente, Ellis et al. (2007) avaliaram o comportamento, durante o armazenamento, de sementes de carambola e as reclassificaram como intermediárias, ou seja, seriam capazes de tolerar reduções do teor de água para valores em equilíbrio com umidades relativas entre 40 e $50 \%$, ou seja, entre 7 e $10 \%$ b.u.; no entanto, reduções mais intensas no teor de água poderiam resultar em perda rápida de viabilidade ou mesmo em danos imediatos às sementes. $\mathrm{O}$ comportamento intermediário das sementes de carambola foi confirmado por Liu et al. (2008) no âmbito do projeto Banco de Sementes do Milênio (MSBP), realizado nos Jardins Botânicos Reais de Kew, Reino Unido.

A maioria dos estudos sobre o efeito da secagem na qualidade fisiológica de sementes de fruteiras tropicais é realizada ao sol ou à sombra e, no caso da secagem artificial com ventilação forçada, são poucos os trabalhos realizados sob condições controladas de fluxo de ar seco e razão da mistura do ar de secagem. Processos não controlados de secagem podem promover queda na germinação das sementes ou mesmo plantas pouco vigorosas, trazer baixa produtividade para a lavoura e grande desuniformidade de produção. Além disso, verifica-se também que há forte relação entre a secagem, o período e as condições de armazenamento e o período de viabilidade das sementes (Ellis \& Roberts, 1980). Até o momento, não foram encontrados relatos na literatura sobre o efeito das condições de armazenamento, ou seja, tipo de embalagem e temperatura, sobre a qualidade fisiológica das sementes de carambola.

Como não existem normas específicas para o teste de germinação de sementes de carambola, Ellis et al. (1985) recomendaram, como primeiro passo, que as sementes sejam avaliadas sob temperatura constante de $16^{\circ} \mathrm{C}$, com iluminação de $12 \mathrm{~h}$ a cada ciclo de $24 \mathrm{~h}$. Caso esse procedimento não surta o efeito desejado, deve-se realizar o teste empregandose areia como substrato, em ambiente com temperatura de 25 a $30^{\circ} \mathrm{C}$, com aplicação contínua de luz por 36 dias. A partir dessas informações, Oliveira (2007) realizou testes preliminares de germinação de sementes de carambola e obteve os resultados mais promissores utilizando papel como substrato, empregando germinador regulado a $20-30^{\circ} \mathrm{C}$, com fornecimento diário de $8 \mathrm{~h}$ de luz. A contagem final do teste de germinação foi feita no $35^{\circ}$ dia. No entanto, verificou-se que, na contagem final, ainda havia um número significativo de sementes não germinadas e que tampouco pareciam estar mortas, indicando um possível estado de dormência secundária. A análise visual dessas sementes, tanto externa quanto internamente, indicou que as partes que as compõem permaneciam íntegras, ou seja, nem o tegumento, endosperma ou embrião apresentavam sinais visíveis de deterioração. Ao se realizar o teste de tetrazólio, verificou-se que as sementes permaneciam viáveis. Esses resultados indicaram que, em trabalhos posteriores, a duração do teste de germinação de sementes de carambola deveria ser estendida.

Sendo assim, este trabalho foi desenvolvido com o objetivo de determinar o percentual de germinação e o vigor de sementes secadas por convecção, a $38{ }^{\circ} \mathrm{C}$, ao se estender o tempo de duração do teste de germinação para 84 dias. Avaliou-se, também, o potencial de armazenamento empregando-se dois tipos de embalagem, permeável e impermeável, sob duas condições de estocagem, ambiente a $25^{\circ} \mathrm{C}$ e $61 \%$ de umidade relativa e em câmara a $10{ }^{\circ} \mathrm{C}$ e $82 \%$ de umidade relativa, ao longo de três e seis meses.

\section{MATERIAL E MÉTODOS}

Este trabalho foi realizado no Laboratório de Engenharia Agrícola (LEAG) da Universidade Estadual do Norte Fluminense Darcy Ribeiro (UENF), Campos dos Goytacazes-RJ. Foram utilizadas sementes de carambolas (Averrhoa carambola L.) oriundas de frutos colhidos de 10 
matrizes localizadas em pomar comercial situado na região. A colheita foi realizada em três ocasiões, dando origem a três lotes de frutos, cada um contendo, em média, 650 carambolas. Os frutos foram coletados pela manhã, sendo em seguida transportados para o laboratório para a retirada das sementes. Antes desse procedimento, os frutos foram lavados em água corrente, cortados no sentido longitudinal, separando-os em duas partes, uma com duas e outra com três saliências. Em seguida, as sementes foram retiradas manualmente e transferidas para uma peneira com malha de aço, onde foram lavadas em água corrente, sendo levemente friccionadas umas às outras e também contra a malha, para a retirada do arilo. Foram a seguir enxugadas com papel toalha para retirada da água superficial, sendo então transferidas para um frasco de vidro com tampa rosqueável e vedado com Parafilm. As sementes foram posteriormente armazenadas em câmara do tipo B.O.D. à temperatura de $10 \pm 1^{\circ} \mathrm{C}$, de onde foram retiradas apenas na manhã seguinte, $2 \mathrm{~h}$ antes do início do teste de secagem para que sua temperatura se igualasse à do ambiente.

O potencial fisiológico e o teor de água inicial das sementes foram determinados antes de se iniciar os testes de secagem, seguindo as recomendações propostas pelas Regras para Análise de Sementes (Brasil, 1992). A secagem das sementes foi realizada a $38{ }^{\circ} \mathrm{C}$, com fluxo médio de ar seco de $0,1 \mathrm{~kg} \mathrm{~s}^{-1} \mathrm{~m}^{-2}$, utilizando-se secador protótipo de camada delgada; a câmara de secagem é composta por três bandejas de 0,50 x 0,62 m, construídas de malha de aço galvanizada, dispostas horizontalmente de forma a proporcionar fluxo de ar tangencial. Em cada um dos três testes, o lote correspondente foi dividido em três partes, cada parte ocupando uma das três pequenas bandejas de $0,15 \times 0,15 \mathrm{~m}$, também construídas de malha de aço. As sementes foram espalhadas nos fundos perfurados dessas bandejas, formando uma camada fina de altura correspondente à espessura de uma semente. Essas três bandejas foram dispostas sobre uma das bandejas principais da câmara de secagem.

A massa inicial de sementes em cada uma das bandejas foi determinada antes do início da secagem. Sendo assim, em todos os testes de secagem, a redução do teor de água das sementes foi monitorada por gravimetria, pesando-se o conjunto bandeja-amostra em intervalos regulares de $5 \mathrm{~min}$ nos primeiros $30 \mathrm{~min}$, de $10 \mathrm{~min}$ até os $120 \mathrm{~min}$, de $15 \mathrm{~min}$ até $180 \mathrm{~min}$ e de $30 \mathrm{~min}$ a partir de $180 \mathrm{~min}$, utilizandose uma balança com grau de acurácia de 0,01 g. Depois de serem pesadas, as bandejas retornaram ao secador, efetuandose um rodízio de suas posições, de forma a uniformizar a secagem. A secagem foi interrompida quando o teor de água do produto encontrava-se próximo à condição de equilíbrio para as condições em que foram realizados os testes.

A secagem foi realizada de forma intermitente, em duas etapas, com interrupção da secagem por convecção antes de a semente atingir o teor de água de equilíbrio. Esse procedimento foi adotado preventivamente por dois motivos: em primeiro lugar, as condições do ar ambiente podem não se manter constantes, depois de 8 a $9 \mathrm{~h}$ de secagem, para garantir que as sementes sejam submetidas ao mesmo tratamento, em termos de razão da mistura e fluxo de ar seco. A primeira etapa dos testes de secagem teve início às $09 \mathrm{~h} 30$ min, com término entre 17:00 e 18:00 h, dependendo das condições de secagem. A partir desse horário, começou a ocorrer elevação acentuada na umidade relativa do ambiente e, conseqüentemente, da sua razão da mistura, diminuindo seu potencial de secagem.

A segunda razão para que a secagem intermitente tenha sido adotada nesse trabalho deve-se à possibilidade de obtenção de produto de melhor qualidade final devido à introdução de um ou mais períodos de repouso, entre o inicio e o final do processo de secagem. De acordo com Brooker et al. (1992), quando se interrompe a secagem, existe um gradiente de umidade na semente, estando sua porção central com teor de água mais elevado que sua superfície. A inserção de um período de repouso permite que a umidade seja redistribuída no interior da semente, diminuindo ou mesmo eliminando esse gradiente. Quando isso acontece, há diminuição de algumas das tensões internas geradas na semente pela sua exposição ao ar de secagem ou pela rápida redução do seu teor de água. Ademais, na segunda etapa da secagem, devido à redistribuição de umidade, há maior facilidade de retirada da água residual até o nível desejado, mantendo assim a integridade e a qualidade da semente.

A velocidade do ar de secagem foi medida utilizandose um anemômetro de pás rotativas posicionado na saída de ar do secador. As leituras de velocidade e temperatura foram registradas ao final de cada pesagem. A temperatura do ar de secagem foi medida utilizando-se um termômetro de mercúrio, com divisão da escala igual a $1{ }^{\circ} \mathrm{C}$, que foi colocado logo abaixo da câmara de secagem. A temperatura e umidade do ar ambiente foram medidas com aparelho digital, sendo também registrados continuamente em termohigrógrafo. Pretendeu-se, com este monitoramento, avaliar as demais propriedades psicrométricas do ar de secagem, como entalpia, razão de mistura e volume específico, utilizando o programa computacional GRAPSI desenvolvido por Melo et al. (2004).

Terminada a secagem, parte da amostra foi utilizada 
para determinação do teor de água final utilizando-se o método-padrão e a outra parte foi utilizada para realização dos testes de qualidade fisiológica. $\mathrm{O}$ poder germinativo e $o$ vigor das sementes (IVG e $t_{\text {médio }}$ ) foram avaliados logo depois da secagem, para determinação do efeito imediato da temperatura do ar de secagem sobre a germinação.

$\mathrm{O}$ restante das sementes secas foi subdividido em 12 porções com aproximadamente o mesmo número de sementes, sendo seis porções acondicionadas em embalagem permeável, do tipo papel Kraft, de $20 \times 10 \mathrm{~cm}$; as demais foram acondicionadas em embalagem flexível impermeável multifoliada com a seguinte especificação: filme de poliéster de $12 \mu \mathrm{m}(\mathrm{PET})+$ tinta branca + adesivo + alumínio 8 $\mu \mathrm{m}+$ adesivo + filme de polietileno transparente de $15 \mathrm{~g}$ $\mathrm{m}^{-2}$ (PEBD). A taxa de permeabilidade ao oxigênio desta embalagem, nas CNTP, é de $0,32 \mathrm{~cm}^{3} \mathrm{~m}^{-2} \mathrm{dia}^{-1}$; a taxa de permeabilidade ao vapor d'água, a $38^{\circ} \mathrm{C}$ e $90 \%$ de umidade relativa, é de $0,036 \mathrm{~g} \mathrm{~m}^{-2} \mathrm{dia}^{-1}$. Depois do acondicionamento das sementes, as embalagens impermeáveis foram seladas a vácuo. As sementes acondicionadas nestas embalagens foram armazenadas em dois tipos de ambiente: câmara do tipo B.O.D. a $10 \pm 1{ }^{\circ} \mathrm{C}$ e sobre bancada em condições de laboratório, por 90 e 180 dias de armazenamento, para verificação do efeito latente da secagem. Tanto a temperatura quanto a umidade relativa nesses dois ambientes foram medidas durante todo o período de armazenamento, em intervalos de $1 \mathrm{~h}$, utilizandose termohigrômetro com sistema automático de aquisição de dados.

$O$ teste de germinação foi realizado empregandose quatro repetições de 50 sementes, em rolo de papel Germitest com quantidade de água equivalente a 2,5 vezes a sua massa e colocadas em germinador regulado a $20{ }^{\circ} \mathrm{C}$, para o período noturno, e $30^{\circ} \mathrm{C}$, para o período diurno, com fornecimento de luz por $8 \mathrm{~h}$. A primeira contagem foi feita no $14^{\circ}$ dia e as demais em intervalos regulares de 7 dias, num total de onze avaliações. Os resultados foram expressos em porcentagem de sementes germinadas. Para estimativa do vigor, determinou-se o tempo médio de germinação $\left(\mathrm{t}_{\text {médio }}\right)$ e o índice de velocidade de germinação (IVG), calculados de acordo com as fórmulas descritas em Borghetti \& Ferreira (2004).

A análise estatística dos dados foi feita empregandose o método de Amostragem Simples ao Acaso (Cochran, 1977). Nesse método, cada semente representa uma unidade experimental. Os percentuais de vigor e germinação, para cada situação estudada, foram analisados e comparados por meio de intervalos de confiança, para o nível de significância de $5 \%$. As amostras foram dimensionadas considerando $\alpha=$
$5 \%$ e d $=5 \%$ da média amostral. Nas figuras mostrando os resultados da qualidade fisiológica obtidos pelo método da amostragem, a ocorrência de qualquer nível de superposição das barras horizontais que representam os intervalos de confiança para germinação e vigor, revela que não há diferença significativa entre os tratamentos.

\section{RESULTADOS E DISCUSSÃO}

$\mathrm{Na}$ Tabela 1 são apresentados os valores médios de temperatura e razão da mistura do ar ambiente, as condições iniciais e finais das sementes, os parâmetros de secagem utilizados nos testes experimentais 1, 2 e 3, e seus resultados. Observa-se que, na primeira etapa da secagem, foram necessárias de 8 a $9 \mathrm{~h}$ para reduzir o teor de água inicial das sementes de cerca de $48 \%$ b.u. para valores entre 8,6 a $14 \%$ b.u., ou seja, a taxa de secagem média foi de 4,3 pontos percentuais de água retirados por hora de secagem. Depois de interrompida a secagem, as sementes permaneceram em repouso por 14 a $15 \mathrm{~h}$, na condição do ambiente, antes de se iniciar a etapa final de secagem. As condições médias de temperatura e umidade relativa do ambiente, durante o período de repouso, para os três testes, foram de $29^{\circ} \mathrm{C}$ e $60 \% ; 31^{\circ} \mathrm{C}$ e $67 \% ; 29^{\circ} \mathrm{C}$ e $73 \%$; respectivamente. A razão da mistura, para cada um desses pares de valores, foi de 0,015; 0,019 e 0,018 $\mathrm{kg}$ de vapor d'água por $\mathrm{kg}$ de ar seco. O valor mais elevado da razão de mistura, observado para as condições do teste 2 , pode ter sido responsável pela manutenção do teor de água das sementes em $8,6 \%$ b.u. durante o período de repouso. No entanto, para as sementes empregadas nos testes 1 e 3, verifica-se que houve secagem parcial, com reduções de 1,6 e 2,8 pontos percentuais de teor de água, respectivamente. Novamente, ao menor valor de razão da mistura do ar ambiente correspondeu redução mais acentuada no teor de água, também acompanhada de maior valor para a taxa de secagem $(0,1$ e 0,2 pontos percentuais de água retiradas por hora de repouso, para os testes 1 e 3 , respectivamente).

No segundo dia de secagem, os testes tiveram início às 8 $\mathrm{h}$ e, à exceção do teste 2 , tiveram duração de cerca de $4 \mathrm{~h}$. As sementes empregadas nesse teste foram as que tiveram a maior redução no teor de água ao final do primeiro dia de secagem, provavelmente devido ao maior valor do fluxo de ar seco. Observa-se que, no teste 2, além da situação relativamente desfavorável em termos de condições ambientais durante o repouso, no segundo dia de secagem, não se logrou elevar a temperatura do ar além de $36{ }^{\circ} \mathrm{C}$. A associação dessas duas condições fez com que as sementes entrassem em equilíbrio higroscópico com o ar de secagem em um valor 
comparativamente elevado, $8,7 \%$ b.u., e, portanto, não tendo sido possível uma redução adicional do teor de água. Nos testes 1 e 3 , o teor de água foi reduzido de cerca de $11 \%$ b.u. para 7 e $6 \%$ b.u., respectivamente. A maior taxa de secagem das sementes no teste 3 pode ser explicada pelo menor valor da razão da mistura e maior valor do fluxo de ar seco.

TABELA 1. Condições médias do ar e das sementes de carambola, tempo de secagem e data de realização dos testes 1 , 2 e 3.

\begin{tabular}{|c|c|c|c|}
\hline Teste & 1 & 2 & 3 \\
\hline Data de realização da primeira etapa da secagem & $16 / 03 / 2006$ & 21/03/2006 & 27/03/2006 \\
\hline \multicolumn{4}{|l|}{ Condições do ar ambiente: } \\
\hline Temperatura, ${ }^{\circ} \mathrm{C}$ & $31,0 \pm 0,8$ & $30,8 \pm 0,4$ & $28,5 \pm 0,9$ \\
\hline Razão da mistura, $\mathrm{kg} \mathrm{kg}^{-1}$ & $0,018 \pm 0,002$ & $0,017 \pm 0,001$ & $0,018 \pm 0,001$ \\
\hline \multicolumn{4}{|l|}{ Condições de secagem: } \\
\hline Temperatura, ${ }^{\circ} \mathrm{C}$ & $38,5 \pm 1,1$ & $38,0 \pm 1,0$ & $37,5 \pm 2,2$ \\
\hline Fluxo de ar seco, $\mathrm{kg} \mathrm{s}^{-1} \mathrm{~m}^{-2}$ & $0,970 \pm 0,028$ & $1,042 \pm 0,031$ & $0,979 \pm 0,081$ \\
\hline \multicolumn{4}{|l|}{ Condições iniciais do produto: } \\
\hline Temperatura, ${ }^{\circ} \mathrm{C}$ & 30,8 & 30,8 & 28,6 \\
\hline Teor de água, \% b.u. & $47,9 \pm 0,3$ & $46,9 \pm 0,7$ & $49,2 \pm 0,8$ \\
\hline \multicolumn{4}{|l|}{ Condições finais do produto: } \\
\hline Temperatura, ${ }^{\circ} \mathrm{C}$ & 38,0 & 39,0 & 33,0 \\
\hline Teor de água, \% b.u. & $12,2 \pm 2,5$ & $8,6 \pm 0,9$ & $13,8 \pm 0,8$ \\
\hline \multicolumn{4}{|l|}{ Tempo de secagem: } \\
\hline Tempo, h & 8,5 & 9,0 & 8,0 \\
\hline Data de realização da segunda etapa da secagem & $17 / 03 / 2006$ & 22/03/2006 & 28/03/2006 \\
\hline \multicolumn{4}{|l|}{ Condições do ar ambiente: } \\
\hline Temperatura, ${ }^{\circ} \mathrm{C}$ & $30,7 \pm 0,3$ & $29,3 \pm 0,2$ & $27,2 \pm 0,3$ \\
\hline Razão da mistura, $\mathrm{kg} \mathrm{kg}^{-1}$ & $0,017 \pm 0,001$ & $0,018 \pm 0,000$ & $0,015 \pm 0,002$ \\
\hline \multicolumn{4}{|l|}{ Condições de secagem: } \\
\hline Temperatura, ${ }^{\circ} \mathrm{C}$ & $37,1 \pm 0,8$ & $36,0 \pm 2,0$ & $38,0 \pm 0,6$ \\
\hline Fluxo de ar seco, $\mathrm{kg} \mathrm{s}^{-1} \mathrm{~m}^{-2}$ & $1,051 \pm 0,040$ & $1,038 \pm 0,013$ & $1,067 \pm 0,029$ \\
\hline \multicolumn{4}{|l|}{ Condições iniciais do produto: } \\
\hline Temperatura, ${ }^{\circ} \mathrm{C}$ & 30,7 & 34,0 & 28,6 \\
\hline Teor de água, \% b.u. & $10,6 \pm 2,3$ & $8,6 \pm 0,9$ & $11,0 \pm 0,8$ \\
\hline \multicolumn{4}{|l|}{ Condições finais do produto: } \\
\hline Temperatura, ${ }^{\circ} \mathrm{C}$ & 37,1 & 36,0 & 39,0 \\
\hline Teor de água, \% b.u. & $6,9 \pm 0,7$ & $8,7 \pm 0,3$ & $5,9 \pm 0,2$ \\
\hline \multicolumn{4}{|l|}{ Tempo de secagem: } \\
\hline Tempo, h & 4,0 & 1,0 & 4,0 \\
\hline
\end{tabular}

A combinação das variáveis avaliadas nesse trabalho resultou em oito condições experimentais de armazenamento, além dos tratamentos correspondentes às sementes antes e imediatamente depois da secagem. Apresenta-se, na Tabela 
2, o resumo dessas condições experimentais de secagem (temperatura e teores de água inicial e final) e os valores mínimo, médio e máximo, tanto da temperatura quanto da umidade relativa, nos dois ambientes de armazenamento. Os resultados referentes ao teste de germinação das sementes de carambola para as condições de 1 a 9 , estimados aos 84 dias do teste de germinação, também são apresentados na Tabela 2, mostrando o percentual de sementes germinadas e, dentre elas, as que originaram plântulas normais e anormais, além do percentual de sementes dormentes e deterioradas. Foi classificada como plântula normal aquela que se apresentou vigorosa, com parte aérea e sistema radicular bem desenvolvidos e tamanho do hipocótilo igual ou superior a $2 \mathrm{~cm}$. A contagem para a condição 1 foi terminada aos 56 dias, pois o substrato se desintegrou, não permitindo a continuação da avaliação. As sementes que não germinaram encontravam-se completamente deterioradas. A contagem para as sementes logo depois da secagem foi interrompida aos 42 dias, devido à contaminação das sementes e substrato por diversos tipos de microorganismos; na ocasião, apenas $20 \%$ das sementes haviam germinado. Oliveira (2007) secou sementes de carambola, de diversas procedências, a 30,34 e $38{ }^{\circ} \mathrm{C}$, e não observou efeito imediato deletério da temperatura de secagem sobre a germinação. No entanto, no presente trabalho, observa-se que houve redução significativa do percentual de germinação imediatamente depois da secagem a $38^{\circ} \mathrm{C}$. No entanto, como explicado anteriormente, é mais provável que essa redução drástica no percentual de germinação, de 87 para $20 \%$, deva-se à contaminação das sementes por microorganismos, e sua consequente deterioração, do que ao efeito da temperatura de secagem propriamente dita.

TABELA 2. Resumo das condições experimentais durante a secagem e armazenamento das sementes de carambola, percentual de sementes que germinaram, dando origem a plântulas normais e anormais, e o percentual de sementes dormentes e deterioradas.

\begin{tabular}{|c|c|c|c|c|c|c|c|c|c|c|c|c|c|c|}
\hline \multirow[t]{2}{*}{ Condição } & \multirow[t]{2}{*}{$\begin{array}{l}\text { Tempo (dias) e } \\
\text { condição de } \\
\text { armazena- } \\
\text { mento }\end{array}$} & \multirow[t]{2}{*}{$\begin{array}{c}\text { Tipo de } \\
\text { embalagem }\end{array}$} & \multirow[t]{2}{*}{$\begin{array}{c}\text { Temperatura } \\
\text { de secagem } \\
\left(1^{\circ} \text { e } 2^{\circ} \text { dia }\right) \\
\left({ }^{\circ} \mathrm{C}\right)\end{array}$} & \multirow[t]{2}{*}{$\mathrm{U}_{\mathrm{i}} \stackrel{1 /}{\mathrm{L}}$} & \multirow[t]{2}{*}{$\mathrm{J}_{\mathrm{f}} \underline{2 l}$} & \multicolumn{3}{|c|}{$\begin{array}{l}\text { Temperatura no } \\
\text { ambiente de } \\
\text { armazenamento } \\
\left({ }^{\circ} \mathrm{C}\right)\end{array}$} & \multicolumn{2}{|c|}{$\begin{array}{c}\text { Umidade } \\
\text { relativa no } \\
\text { ambiente de } \\
\text { armazenamento } \\
(\%)\end{array}$} & \multicolumn{4}{|c|}{$\begin{array}{c}\text { Classificação e percentual de } \\
\text { sementes e plântulas aos } 84 \\
\text { dias do teste de germinação } \\
(\%)\end{array}$} \\
\hline & & & & & & med & $\min$ & $\max$ & med $\min$ & $\max$ & normal & ormal & dorm $\frac{3 l}{}$ & deter 4 l \\
\hline 1 & $*$ & - & - & 47,94 & 47,9 & - & - & 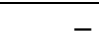 & $-\quad-$ & - & 87,0 & 0 & 0 & 13,0 \\
\hline 2 & 90/B.O.D. & meável & e 36,0 & 8,7 & 9,3 & 9,6 & 7,8 & 11,8 & $81,570,7$ & 87,3 & 87 & 2,5 & 7,0 & 3,5 \\
\hline 3 & 180/B.O.D. & permeável & 38,5 e 37,1 & 6,9 & 9,4 & 9,8 & 7,8 & 13,3 & $81,857,3$ & 93,8 & 55,0 & 16,0 & 1,0 & 28,0 \\
\hline 4 & 90/Ambiente & permeável & 37,5 e 38,0 & 5,9 & 6,72 & 25,1 & 21,7 & 31,1 & $60,934,7$ & 76,0 & 57,0 & 12,5 & 10,0 & 20,5 \\
\hline 5 & 180/Ambiente & 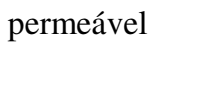 & 38,5 e 3 & 6,9 & 6,82 & 25,0 & 19,0 & 31,9 & $61,025,9$ & 91,7 & 9,5 & 17,0 & 4,0 & 69,5 \\
\hline 6 & 90/B.O.D. & Imperm & Jo, & 8,7 & 8,4 & 9,6 & 7,8 & 8 & $81,570,7$ & 87,3 & 86,5 & 1,0 & 7,0 & 5,5 \\
\hline 7 & 180/B.O.D. & Impermeável & 38,5 e 37,1 & 6,9 & 7,0 & 9,8 & 7,8 & 13,3 & $81,857,3$ & 93,8 & 82,5 & 7,0 & 4,0 & 6,5 \\
\hline 8 & 90/Ambiente & Impermeável & 37,5 e 38,0 & 5,9 & 5,7 & 25,1 & 21,7 & 31,1 & $60,934,7$ & 76,0 & 76,5 & 12,0 & 5,5 & 6,0 \\
\hline 9 & 180/Ambiente & Impermeável & 38,5 e 37,1 & 6,9 & 7,3 & 25,0 & 19,0 & 31,9 & $61,025,9$ & 91,7 & 56,5 & 29,5 & 1,0 & 13,0 \\
\hline
\end{tabular}

1/ Teor de água inicial (\% b.u.); 2/ Teor de água final (\% b.u.); 3/ Semente dormente; 4/ Semente deteriorada; * sementes sem secar.

$\mathrm{Na}$ Figura 1 encontram-se os intervalos de confiança, a $95 \%$ de probabilidade, para o percentual de germinação, antes da secagem e também para sementes armazenadas sob diversas condições em embalagem permeável. Os valores correspondentes para sementes armazenadas em embalagem impermeável estão na Figura 2.

Quanto à utilização de embalagem permeável para estocagem de sementes de carambola, verifica-se, na Figura 1, que apenas aquelas armazenadas em B.O.D. por 90 dias não apresentaram redução significativa no percentual de germinação em relação àquele observado quando as sementes foram retiradas dos frutos. O período de armazenamento de 180 dias teve influência negativa sobre a germinação para as duas condições de estocagem, temperatura controlada em B.O.D e em ambiente. Aliás, a condição ambiente foi desfavorável para qualquer das situações avaliadas, não sendo, portanto, indicada para o armazenamento de sementes de carambola em embalagem permeável. 


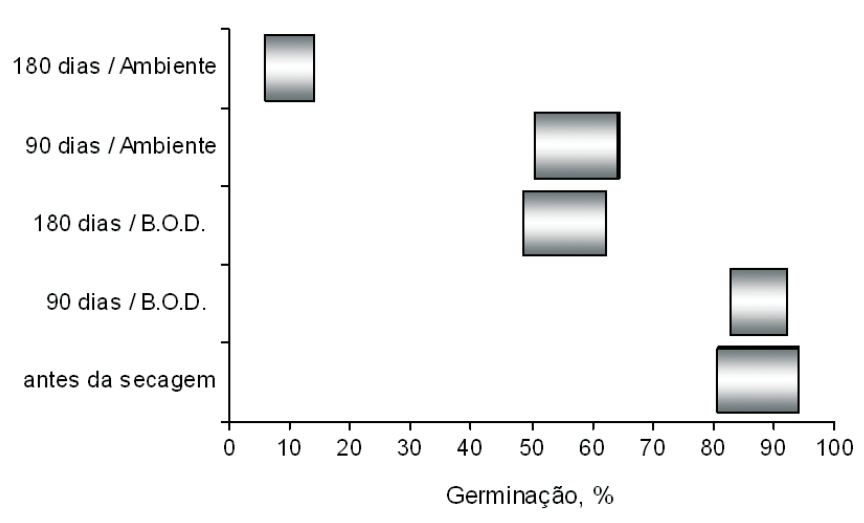

FIGURA 1. Intervalos de confiança, a $95 \%$ de probabili-dade, para germinação de sementes de carambola, antes da secagem e armazenadas por 90 e 180 dias, a $10{ }^{\circ} \mathrm{C}$ em B.O.D e em temperatura ambiente, em embalagem permeável.

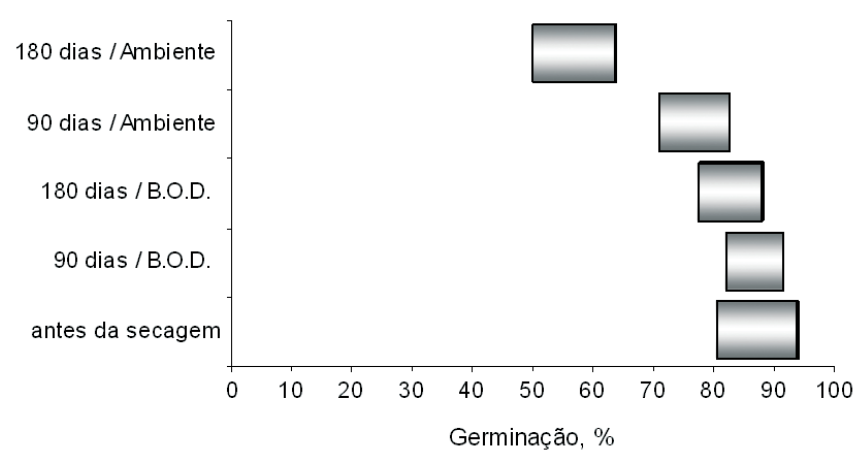

FIGURA 2. Intervalos de confiança, a 95\% de probabili-dade, para germinação de sementes de carambola, antes da secagem e armazenadas por 90 e 180 dias, a $10{ }^{\circ} \mathrm{C}$ em B.O.D e em temperatura ambiente, em embalagem impermeável a vácuo.

Para sementes armazenadas em embalagemimpermeável, Figura 2, a única condição desfavorável foi o armazenamento por 180 dias em condição ambiente $\left(25,0 \pm 1,7^{\circ} \mathrm{C}\right.$ e umidade relativa de $61,0 \pm 7,1 \%$ ). Portanto, à exceção dessa condição, pode-se concluir que não houve influência significativa do período e tampouco das condições de armazenamento sobre a germinação de sementes de carambola estocadas em embalagem impermeável a vácuo. Ademais, comparandose as Figuras 1 e 2, observa-se que o armazenamento em embalagem impermeável a vácuo resultou em percentuais de germinação consistentemente maiores que aqueles observados em embalagem permeável. Esses resultados também confirmam, ao contrário do que se afirma na literatura (Nakasone \& Paull, 1988; Donadio et al., 2001), que as sementes de carambola podem manter o percentual de germinação mesmo depois de ter seu teor de água reduzido de $48 \%$ b.u. para valores entre 6 e $8 \%$ b.u., empregando-se temperatura de secagem de $38{ }^{\circ} \mathrm{C}$, podendo, inclusive, ser armazenadas por 90 ou 180 dias, a $10^{\circ} \mathrm{C}$, e por 90 dias, em temperatura ambiente em embalagem impermeável a vácuo.

Apresentam-se, nas Figuras 3 e 4, os valores médios e os respectivos intervalos de confiança do IVG de sementes de carambola armazenadas por 90 e 180 dias, em embalagem permeável e impermeável, respectivamente. Os valores correspondentes para o $t_{\text {médio }}$ encontram-se nas Figuras $5 \mathrm{e}$ 6 , respectivamente. A análise dos valores mostrados nas Figuras 3 e 4 evidencia que, em geral e independentemente do período e da temperatura de armazenamento, o vigor estimado pelo IVG foi consistentemente maior para as sementes estocadas em embalagens impermeáveis a vácuo. Esse mesmo comportamento foi verificado para o percentual de germinação mostrado na Figura 2. Para sementes estocadas em embalagem permeável, apenas aquelas armazenadas por 90 dias em B.O.D. a $10{ }^{\circ} \mathrm{C}$ mostraram desempenho semelhante em termos de IVG.

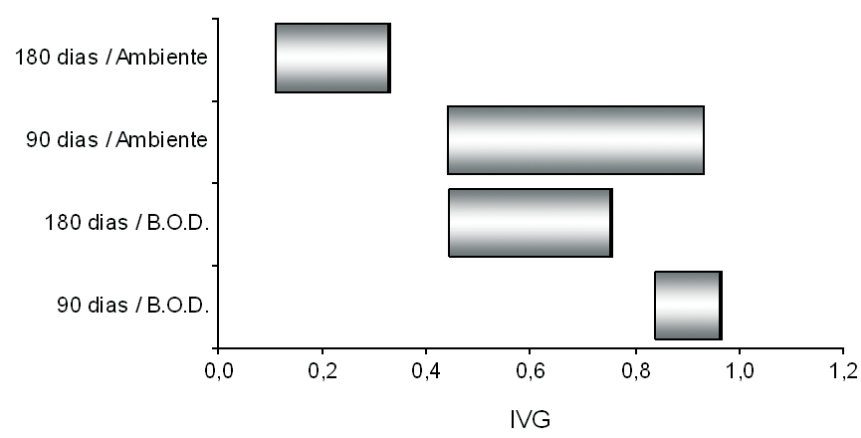

FIGURA 3. Intervalos de confiança, a 95\% de probabili-dade, para o IVG de sementes de carambola armazenadas por 90 e 180 dias, a cerca de 10 ${ }^{\circ} \mathrm{C}$ em B.O.D e em temperatura ambiente, em embalagem permeável. 


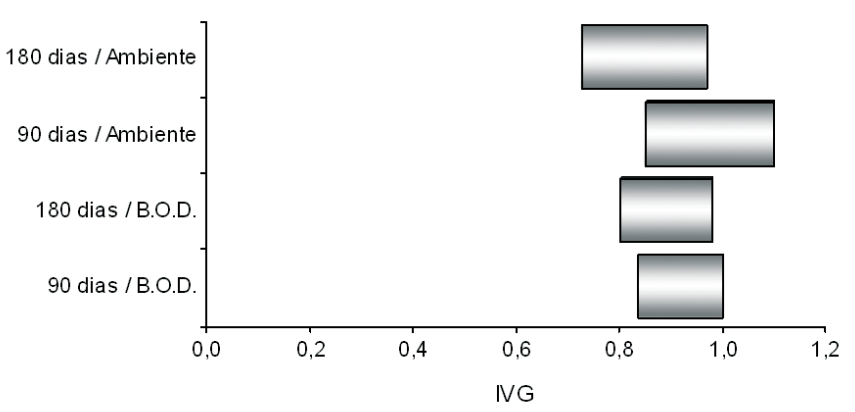

FIGURA 4. Intervalos de confiança, a 95\% de probabili-dade, para o IVG de sementes de carambola armazenadas por 90 e 180 dias, a cerca de 10 ${ }^{\circ} \mathrm{C}$ em B.O.D e em temperatura ambiente, em embalagem impermeável.

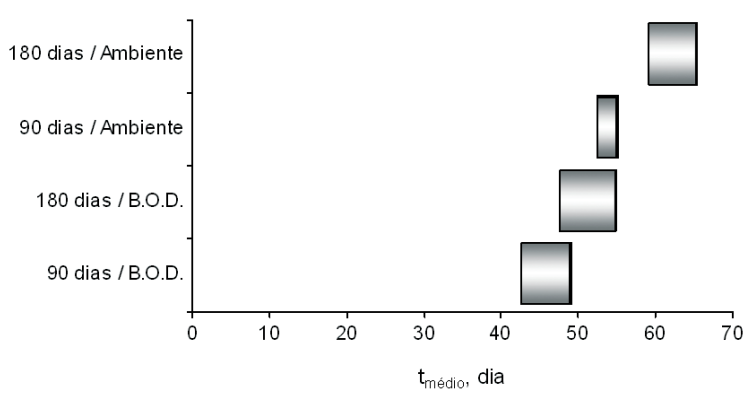

FIGURA 5. Intervalos de confiança, a 95\% de probabili-dade, para o tmédio de sementes de carambola armazenadas por 90 e 180 dias, a cerca de $10{ }^{\circ} \mathrm{C}$ em B.O.D e em temperatura ambiente, em embalagem permeável.

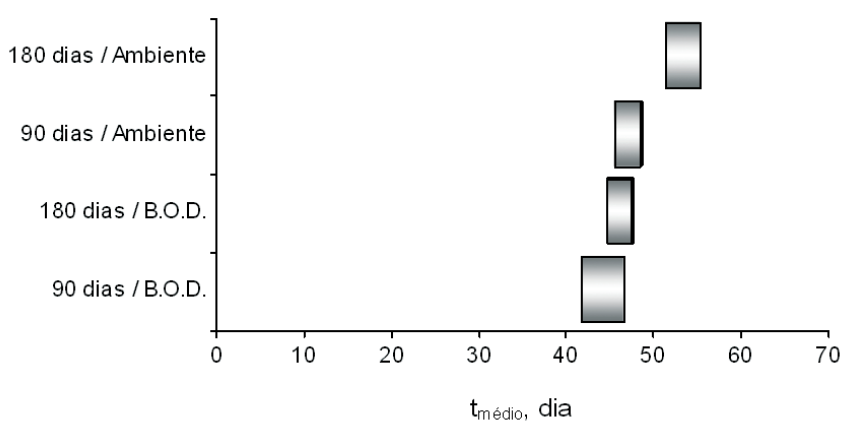

FIGURA 6. Intervalos de confiança, a $95 \%$ de probabili-dade, para o $t_{\text {médio }}$ de sementes de carambola armazenadas por 90 e 180 dias, a cerca de 10 ${ }^{\circ} \mathrm{C}$ em B.O.D e em temperatura ambiente, em embalagem impermeável.
$\mathrm{O}$ vigor estimado pelo $\mathrm{t}_{\text {médio }}$ (Figuras 5 e 6 ) indica que $\mathrm{o}$ melhor desempenho foi obtido para sementes armazenadas a $10{ }^{\circ} \mathrm{C}$, em embalagens impermeáveis. Os valores não devem ser comparados com aqueles obtidos para as sementes antes e imediatamente após a secagem, uma vez que estes testes foram interrompidos antes dos 84 dias. Para a condição ambiente $\left(25^{\circ} \mathrm{C}\right)$, assim como havia ocorrido para o IVG, o $t_{\text {médio }}$ só foi comparável às melhores condições obtidas em embalagem impermeável para sementes armazenadas por 90 dias em B.O.D. a $10^{\circ} \mathrm{C}$. Observa-se, portanto, que o melhor desempenho fisiológico, considerando os três parâmetros avaliados (germinação, IVG e $t_{\text {médio }}$ ), foi aquele obtido para sementes armazenadas em embalagem impermeável, a 10 ${ }^{\circ} \mathrm{C}$, por períodos de 90 ou 180 dias. Sendo assim, no presente trabalho, os índices de vigor avaliados foram compatíveis com os resultados obtidos no teste de germinação. Esses resultados estão de acordo com os obtidos por Brown \& Meyer (1988), que testaram 18 índices para avaliação de vigor de sementes, e concluíram que, para lotes com germinação semelhante, os índices são capazes de corroborar os resultados obtidos nos testes de germinação. No entanto, os índices testados não foram adequados para diferenciar lotes de sementes classificados como de qualidade superior (alto percentual de germinação) daqueles de qualidade inferior.

\section{CONCLUSÕES}

Sementes de carambola podem ser armazenadas em embalagem impermeável a vácuo, sem redução do poder germinativo, por 90 ou 180 dias a $10{ }^{\circ} \mathrm{C}$, e por 90 dias em condição ambiente $\left(25{ }^{\circ} \mathrm{C}\right.$ e $61 \%$ de umidade relativa). As sementes podem, também, ser armazenadas por 90 dias, sob refrigeração, em embalagem permeável. Independentemente do período e da temperatura de armazenamento, o vigor estimado pelo IVG e $t_{\text {médio }}$ é consistentemente superior para as sementes estocadas em embalagens impermeáveis a vácuo.

\section{AGRADECIMENTOS}

Ao CNPq, FAPERJ, FINEP e International Foundation for Science (IFS), pelo apoio financeiro.

\section{REFERÊNCIAS}

BORGHETTI, F.; FERREIRA, A.G. Interpretação de resultados de germinação. In: FERREIRA, A.G., BORGHETTI, F. Germinação: do básico ao aplicado. Porto Alegre: Artmed, 2004. p.209-222. 
BRASIL. Ministério da Agricultura e Reforma Agrária. Regras para análise de sementes. Brasília, DF: SNDA/ DNDV/CLAV, 1992. 365p.

BROOKER, D.B.; BAKKER-ARKEMA, F.W.; HALL, C.W. Drying and storage of grains and oilseeds. New York: Van Nostrand Reinhold, 1992. 450p.

BROWN, R.F.; MAYER, D.G. Representing cumulative germination. 1. A critical analysis of single-value germination indices. Annals of Botany, v.61, n.2, p.117-125, 1988.

COCHRAN, W.G. Sampling techniques. New York: John Wiley \& Sons, Inc., 1977. 448 p.

CRANE, J.H. The carambola. Fact Sheet HS-12. University of Florida: IFAS Extension, 1994. 6p.

DONADIO, L.C.; SILVA, J.A.A.; ARAÚJO, P.S.R.; PRADO, R.M. Caramboleira (Averrhoa carambola L.). Jaboticabal: Sociedade Brasileira de Fruticultura, 2001. $81 \mathrm{p}$.

ELLIS, R.H.; ROBERTS, E.H. Improved equations for the prediction of seed longevity. Annals of Botany, v.45, n.1, p.13-30, 1980.

ELLIS, R.H.; HONG, T.D.; ROBERTS, E.H. Oxalidaceae. Handbook of seed technology for genebanks. In: ELLIS, R.H.; HONG, T.D.; ROBERTS, E.H. (Ed.).
Compendium of specific germination information and test recommendations. Rome: International Board for Plant Genetic Resources, 1985. Chapter 52, v.2

ELLIS, R.H.; MAI-HONG, T.; HONG, T.D.; TAN, T.T.; XUAN-CHUONG, N.D.; HUNG, L.Q.; NGOC-TAM, B.; LE-TAM, V.T. Comparative analysis by protocol and key of seed storage behaviour of sixty Vietnamese tree species. Seed Science and Technology, v.35, n.2, p.460-476, 2007.

LIU, K.; EASTWOOD, R.J.; FLYNN, S.; TURNER, R.M.; STUPPY, W.H. Seed information Database. Royal Botanic Gardens, Kew: Data \& Publications. Release 7.1. Disponível em: $<$ http://www.kew.org/data/sid $>$ Acesso em: 3 nov. 2008.

MELO, E.C.; LOPES, D.C.; CORREAA, P.C. GRAPSIPrograma computacional para o cálculo das propriedades psicrométricas do ar. Engenharia na Agricultura, v.12 n.2, p.154-162, 2004.

NAKASONE, H. Y.; PAULL, R. E. Tropical fruits. Oxon: CAB International, 1998. 445p.

OLIVEIRA, M.T.R. Secagem, armazenamento e qualidade fisiológica de sementes de carambola (Averrhoa carambola L.). 2007. 93f. Tese (Mestrado) - Universidade Estadual do Norte Fluminense Darcy Ribeiro, Campos dos Goytacazes. 